UchwAŁA nr CIX/2894/18 Rady Miasta Krakowa z dnia 12 września 2018 r. w sprawie uchwalenia miejscowego planu zagospodarowania przestrzennego „Dla wybranych obszarów przyrodniczych miasta Krakowa" - etap A. Dziennik Urzędowy Województwa Małopolskiego z 2018 r., poz. 6561.

Winther J. L. \& Friedman W. E. 2007. Arbuscular mycorrhizal symbionts in Botrychium (Ophioglossaceae). - American Journal of Botany 94(7): 1248-1255.

WóJCIAK H. 2007. Porosty, mszaki, paprotniki. s. 368. MULTICO Oficyna Wydawnicza, Warszawa.

ZAJĄC M. \& ZAJĄC A. (red.) 1998. Atlas rozmieszczenia roślin naczyniowych w woj. krakowskim. Gatunki prawnie chronione, ginące, narażone i rzadkie. s. 134. Nakładem Pracowni Chorologii Komputerowej Instytutu Botaniki Uniwersytetu Jagiellońskiego, Kraków.

ZAJĄC M. \& ZAJĄC A. 2009. Elementy geograficzne rodzimej flory Polski. s. 94. Nakładem Pracowni Chorologii Komputerowej Instytutu Botaniki Uniwersytetu Jagiellońskiego, Kraków.

Zając M., Zając A. \& Zemanek B. (red.) 2006. Flora Cracoviensis Secunda (Atlas). s. xii + 291. Pracownia Chorologii Komputerowej Instytutu Botaniki Uniwersytetu Jagiellońskiego, Kraków.

ZapaŁowicz H. 1906. Krytyczny przegląd roślinności Galicyi 1. s. 296. Nakładem Akademii Umiejętności, Kraków.

ZARZYCKI K. \& SzeląG Z. 2006. Czerwona lista roślin naczyniowych w Polsce. - W: Z. MireK, K. ZARZYCKI, W. WoJewoda \& Z. SzeląG (red.), Czerwona lista roślin i grzybów Polski, s. 9-20. W. Szafer Institute of Botany, Polish Academy of Sciences, Kraków.

Zarzycki K., Trzcińska-Tacik H., Różański W., Szeląg Z., WoŁeK J. \& KorZeniak U. 2002. Ecological indicator values of vascular plants of Poland. - W: Z. MireK (red.), Biodiversity of Poland 2, s. 183. W. Szafer Institute of Botany, Polish Academy of Sciences, Kraków.

ŻMUdA A. J. 1920. Rzadsze lub nowe rośliny flory krakowskiej. - Sprawozdanie Komisji Fizjograficznej 53-54: 30-76.

Magdalena Zarzyka-Ryszka (autor korespondencyjny), Instytut Botaniki im. W. Szafera Polskiej Akademii Nauk, ul. Lubicz.46, 31-512 Kraków, Polska, e-mail: m.zarzyka@botany.pl

PRZEMYSEAw Ryszka, Uniwersytet Jagielloński, Instytut Nauk o Środowisku, ul. Gronostajowa 7,30-387 Kraków, Polska,e-mail: przemyslaw.ryszka@uj.edu.pl

Wptynęto: 19.01.2020 r.; przyjęto do druku: 18.09.2020 r.

DOI: https://doi.org/10.35535/ffgp-2020-0039

\title{
Nowe stanowisko Polystichum aculeatum (Dryopteridaceae) w projektowanym rezerwacie przyrody „Czarcia Kępa” na Pojezierzu Litewskim
}

Polystichum aculeatum (L.) Roth (paprotnik kolczysty) jest byliną spotykaną przede wszystkim w Karpatach, Sudetach i na wyżynach południowej Polski (ZAJĄC \& ZAJĄC 2001), wyróżniającą dla górsko-podgórskich lasów zboczowych ze związku Tilio platyphyllis-Acerion pseudoplatani (MATUSZKIEWICZ 2001), w Polsce objętą ścisłą ochroną gatunkową (ROZPORZĄDZENIE 2014). 
W północno-wschodniej Polsce gatunek znaleziony był dotychczas na pięciu stanowiskach. Dwa z nich, położone na terenie obecnego województwa warmińsko-mazurskiego (koło Dylewa i Olsztyna), już w okresie przedwojennym uznane zostały za zanikłe (ABRoMEIT $i$ in. 1903). Pozostałe stanowiska położone są w województwie podlaskim. Na Pojezierzu Litewskim ,jeden młody egzemplarz" gatunku stwierdzono w latach 80. XX w. w granicach obecnego Wigierskiego Parku Narodowego (SoKоŁOwSKI 1988(1990)) oraz na zboczu nad północno-zachodnim brzegiem jeziora Jaczno w Suwalskim Parku Krajobrazowym (C. Werpachowski, mat. npbl., ok. 1987 r.). W latach 90. XX w. Polystichum aculeatum znaleziono w rezerwacie „Góra Uszeście” nad Bugiem (ADAMOwsKI \& ŁUCZAJ 1995), gdzie obserwowano go jeszcze w 2005 r. (W. Adamowski, D. Wołkowycki, mat. npbl.), ale później już nie odnaleziono (P. Pawlikowski, D. Wołkowycki, mat. npbl.). W Obwodzie Kaliningradzkim P. aculeatum notowano przed blisko 150 laty na Sambii (ABRomeIT i in. 1931-1940), natomiast na Litwie gatunek uznano za wymarły, a następnie odkryto ponownie w 1996 r. (LAZDAuskAITE 1996; TupèIAUSKAITË 2007). Na Białorusi gatunek znany jest $\mathrm{z}$ dwóch współczesnych stanowisk w rejonie Brześcia (a więc położonych niedaleko stanowiska w Mielniku nad Bugiem), jednego koło Mińska oraz historycznego notowania z końca XVIII w. autorstwa B. Jundziłła (SAVČuK 2015).

Polystichum aculeatum jest taksonem o znacznym zróżnicowaniu wewnątrzgatunkowym, obejmującym szereg drobnych gatunków i jako taki posiada bardzo rozległy, ale i bardzo pofragmentowany zasięg. Obejmuje on bardzo rozproszone miejsca występowania na obu półkulach i wszystkich kontynentach oprócz Antarktydy, a także na niektórych oceanicznych wyspach, w tym bardzo odległych. W zachodniej, środkowej i południowej części Europy, jak i w całym w basenie Morza Śródziemnego oraz w rejonie Kaukazu, znajduje się największe znane zgrupowanie stanowisk, a zasięg ma miejscami charakter ciągły (Hultén \& FrIES 1986a, b).

Dnia 22 czerwca 2018 r. znaleziono dotychczas nieznane stanowiska Polystichum aculeatum w projektowanym rezerwacie przyrody „Czarcia Kępa” w dolinie Błędzianki w Nadleśnictwie Gołdap, $3 \mathrm{~km}$ na północ od gminnej wsi Przerośl w województwie podlaskim i ok. 0,75 km na południowy-wschód od wsi Stańczyki w województwie warmińsko-mazurskim. Projektowany rezerwat położony jest w województwie warmińsko-mazurskim przy samej granicy województw, w gminie Dubeninki powiatu gołdapskiego. W regionalizacji fizyczno-geograficznej Polski (KondRACKi 2002; Solon i in. 2018), Czarcia Kępa znajduje się na terenie mezoregionu Pojezierze Zachodniosuwalskie; 54 ${ }^{\circ} 16^{\prime} 57,4^{\prime \prime} \mathrm{N}, 22^{\circ} 39^{\prime} 55,3^{\prime \prime} \mathrm{E}$, w kwadracie ATPOL FA86 (ZAJĄC 1978; VeREY 2017).

Projektowany rezerwat „Czarcia Kępa” stanowi wyspę leśną z drzewostanem o charakterze starodrzewu (ponad 120 lat na większości obszaru), zajmującą przede wszystkim strome zbocza lewobrzeżnej doliny Błędzianki, o wystawie północno-wschodniej, o różnicy wysokości - między dnem doliny a wierzchowiną - przekraczającej $60 \mathrm{~m}$. Zbocze pocięte jest licznymi wąwozami; niektóre z nich zajęte są przez stałe lub okresowe strumienie, biorące swój początek ze źródeł, w tym niewielkich lejów źródliskowych. Pod koniec XIX w. miejsce to było już zalesione (co widać na mapie z 1893 r. z serii Karten des Deutschen Reiches, Generalstabskarte w skali 1:100 000; arkusz 78. Mehlkehmen), co sugeruje trwałość ekologiczną zbiorowiska leśnego w tym miejscu. 
Populacja Polystichum aculeatum składa się z 13 kęp rozrzuconych na powierzchni poniżej 1a, w środkowej części Czarciej Kępy. W miejscu występowania gatunku wykonano zdjęcie fitosocjologiczne. Nazewnictwo roślin naczyniowych przyjęto za MiRKIEM i in. (2002), a mszaków za OchYRĄ i in. (2003).

Zdj. 1. Data: 5.07.2019. Powierzchnia zdjęcia $25 \mathrm{~m}^{2}$. Nachylenie $-65^{\circ}$. Pokrycie warstwy A - 75\%: w obrębie zdjęcia jedynie Corylus avellana 3, spoza powierzchni na zdjęcie nachodzą również korony Carpinus betulus, Picea abies, Populus tremula i Tilia cordata. Pokrycie warstwy B - 20\%: Ribes alpinum 2b, Corylus avellana 1, Acer platanoides + , Lonicera xylosteum + , Tilia cordata + . Pokrycie warstwy C - 65\%: Galeobdolon luteum 2b, Hepatica nobilis 2b, Asarum europaeum 2a, Oxalis acetosella 2a, Aegopodium podagraria 1, Anemone nemorosa 1, Impatiens noli-tangere 1, Mercurialis perennis 1, Polystichum aculeatum 1, Pulmonaria obscura 1, Ranuncuus lanuginosus 1 , Acer platanoides + , Campanula latifolia + , Dryopteris filix-mas + , Geranium robertianum + , Lathyrus vernus + , Ribes alpinum + , Sorbus aucuparia + , Stellaria holostea + , S. nemorum + , Viola mirabilis + , Daphne mezereum r, Tilia cordata $\mathrm{r}$, Ulmus glabra r. Pokrycie warstwy D: 5\%: Brachythecium rutabulum + , Eurhynchium zetterstedti + , Oxyrrhynchium hians 1 , Plagiomnium affine + .

Polystichum aculeatum jest składnikiem runa grądu zboczowego Acer platanoides-Tilia cordata Jutrz.-Trzeb. 1993, rozwijającego się na stromym, zacienionym, gliniastym zboczu o wystawie wschodniej i południowo-wschodniej, w obrębie głębokiego jaru o przeważającym przebiegu SW-NE.

Na terenie projektowanego rezerwatu „Czarcia Kępa”, oprócz Polystichum aculeatum stwierdzono także inne rzadkie i chronione gatunki roślin naczyniowych, takie jak Campanula latifolia, Glyceria nemoralis, Neottia nidus-avis, Platanthera chlorantha i Polygonatum verticillatum. Campanula latifolia jest gatunkiem z krajowej „czerwonej listy” (kategoria NT - gatunek bliski zagrożenia; KAźMIERCZAKOwA i in. 2016), w północnowschodniej Polsce notowanym m.in. na licznych (choć w wielu przypadkach już historycznych) stanowiskach na Warmii i Mazurach (ABROMEIT i in. 1903), a także w Puszczy Knyszyńskiej (SoKoŁowski 1995). W obrębie Pojezierza Litewskiego gatunek podany był jedynie z Puszczy Rominckiej (Aвromeit i in. 1903; WoŁkowyCKi \& PAWLikowsKi 2016). Populacja tego gatunku na terenie Czarciej Kępy składa się przynajmniej z 5000 pędów generatywnych rozrzuconych na całym terenie (przede wszystkim jednak w dolnych częściach jarów przecinających zbocze doliny, gdzie miejscami tworzy gęste skupiska), przez co może stanowić jedną z najobfitszych w Polsce. Biorąc pod uwagę dobry, a przede wszystkich stale poprawiający się (w wyniku procesów sukcesji wtórnej - regeneracji) stan zachowania zboczowych ekosystemów leśnych, najbardziej właściwa wydaje się ochrona zachowawcza i wyłączenie tego kompleksu leśnego z gospodarki leśnej poprzez utworzenie rezerwatu przyrody.

Podziękowania. Dziękuję serdecznie doktorom Wojciechowi Adamowskiemu, Cezaremu Werpachowskiemu i Danowi Wołowyckiemu za udostępnienie swoich niepublikowanych danych o występowaniu Polystichum aculeatum w północno-wschodniej Polsce.

Summary. New locality of Polystichum aculeatum (Dryopteridaceae) in the planned Czarcia Kępa Nature Reserve in the Litewski Lake District. A new locality of Polystichum aculeatum was found in 2018 in the Błędzianka river valley in the Litewski Lake District (Warmia and Masuria Province), where the species has not been recorded since the 19th century. The population consisted of 13 clumps on an extremely steep slope in species-rich broadleaved forest of the Acer platanoides-Tilia cordata community 
within the recently proposed Czarcia Kępa Nature Reserve. In order to protect valuable broadleaved forest with $P$. aculeatum and other rare species - including an abundant population of the rare Campanula latifolia - the planned nature reserve should be established there.

\section{LITERATURA}

Abromeit J., Jentzsch A. \& Vogel G. 1903. Flora von Ost- und Westpreussen. I. Samenpflanzen oder Phanerogamen. 2. Hälfte, I. Teil s. 401-690. Kommission bei R. Friedländer \& Sohn, Berlin.

Abromeit J., Neuhoff W. \& StefFen H. 1931-1940. Flora von Ost- und Westpreussen. s. 685-1248. Kommissionverlag Gräfe und Unzer, Königsberg.

ADAMOWSKI W. \& ŁUCZAJ Ł. 1995. Zagrożenie i program restytucji flory kserotermicznej rezerwatu „Góra Uszeście” w Mielniku nad Bugiem. - Chrońmy Przyrodę Ojczystą 51(1): 80-91.

Hultén E. \& Fries M. 1986a. Atlas of North European vascular plants. North of the Tropic of Cancer. 1. s. xvi + 498. Koeltz Scientific Books, Königstein.

Hultén E. \& Fries M. 1986b. Atlas of North European vascular plants. North of the Tropic of Cancer. 3. s. 969-1172. Koeltz Scientific Books, Königstein.

Kaźmierczakowa R., Bloch-OrŁowska J., Celka Z., Cwener A., Dajdok Z., Michalska-Hejduk D., PAWLIKOWSKI P., SZCZÉŚSIAK E. \& ZIARNeK K. 2016. Polska czerwona lista paprotników i roślin kwiatowych. s. 44. Instytutu Ochrony Przyrody Polskiej Akademii Nauk, Kraków.

KonDRACKI J. 2002. Geografia regionalna Polski. Wyd. 3. s. 441. Wydawnictwo Naukowe PWN, Warszawa. LAZDAUSKAITE Ž. 1996. Polystichum aculeatum (L.) Roth in Lithuania. - Botanica Lithuanica 2(4): 407-409.

Matuszkiewicz W. 2001. Przewodnik do oznaczania zbiorowisk roślinnych Polski. Wyd. 3. s. 537. Wydawnictwo Naukowe PWN, Warszawa.

Mirek Z., Pięroś-Mirkowa H., Zając A. \& ZająC M. 2002. Flowering plants and pteridophytes of Poland. A checklist. - W: Z. MiReK (red.), Biodiversity of Poland. 1, s. 442. W. Szafer Institute of Botany, Polish Academy of Sciences, Kraków.

Ochyra R., Żarnowiec J. \& Bednarek-Ochyra H. 2003. Census catalogue of Polish mosses. s. 372. W. Szafer Institute of Botany, Polish Academy of Sciences, Kraków.

RozPORZĄDZENIE Ministra Środowiska z dnia 9 października 2014 r. w sprawie ochrony gatunkowej roślin (Dz. U. 2014 r., poz. 1409).

SAVČUK S. S. 2015. Mnogorâdnik šypovatyj. Polystichum aculeatum (L.) Roth. - W: V. I. Parfenov, D. V. Dubovik \& A. V. PugačEvskij (red.), Krasnaâ Kniga Respubliki Belarus'. Rasteniâ, s. 24-25. Belaruskaâ Encyklaped'â imâ Petrucâ Broǔki, Minsk.

SoKoŁowski A. W. 1988 (1990). Flora roślin naczyniowych Wigierskiego Parku Narodowego. - Parki Narodowe i Rezerwaty Przyrody 9(4): 5-84.

SokoŁowski A. W. 1995. Rośliny naczyniowe Puszczy Knyszyńskiej. - Parki Narodowe i Rezerwaty Przyrody 14(1): 3-84.

Solon J., Borzyszkowski J., BidŁasik M., Richling A., Badora K. Balon J., Brzezińska-Wójcik T., Chabudziński Ł., Dobrowolski R., Grzegorczyk I., JodŁowski M., Kistowski M., Kot R., Krąż P., Lechnio J., Macias A., Majchrowska A., Malinowska E., Migoń P., Myga-Piątek U., Nita J., PApiŃsKa E., RodZIK J., STRZYŻ M., TerpIŁOWSKI S. \& ZiAJA W. 2018. Physico-geographical mesoregions of Poland: verification and adjustment of boundaries on the basis of contemporary spatial data. - Geographia Polonica 91(2): 143-170.

TupèIauskaitë J. 2007. Polystichum aculeatum (L.) Roth. Miðkinis spyglainis. - W: V. RašOMaviČIUS (red.), Lietuvos raudonoji Knyga, s. 397. Leidykla Lututë, Kaunas. 
VEREY M. 2017. Teoretyczna analiza i praktyczne konsekwencje przyjęcia modelowej siatki ATPOL jako odwzorowania stożkowego definiującego konwersję współrzędnych płaskich na elipsoidę WGS 84. - Fragmenta Floristica et Geobotanica Polonica 24(2): 469-488.

WoŁKowYCKi D. \& PAWLIKowski P. 2016. Zagrożone i chronione gatunki roślin naczyniowych w Puszczy Rominckiej (NE Polska). - Fragmenta Floristica et Geobotanica Polonica 23(1): 13-28

ZAJĄC A. 1978. Założenia metodyczne „Atlasu rozmieszczenia roślin naczyniowych Polski”. - Wiadomości Botaniczne 22(3): 145-155.

ZAJĄC A. \& ZAJĄC M. (red.). 2001. Atlas rozmieszczenia roślin naczyniowych w Polsce. s. xii + 714. Pracownia Chorologii Komputerowej Instytutu Botaniki Uniwersytetu Jagiellońskiego, Kraków.

Pawee Pawlikowski, Zakład Ekologii Roślin i Ochrony Środowiska, Instytut Botaniki, Wydziat Biologii, Centrum Nauk Biologiczno-Chemicznych, Uniwersytet Warszawski, ul. Żwirki i Wigury 101,02-096 Warszawa, Polska; e-mail p.pawlikowski@uw.edu.pl

Wptynęto: 20.11.2019 r.; przyjęto do druku: 17.12.2020 r.

DOI: https://doi.org/10.35535/ffgp-2020-0040

\section{Dryopteris cambrensis (Dryopteridaceae) w Polsce południowej}

Grupa Dryopteris affinis reprezentowana jest na świecie przez siedem gatunków: D. affinis (Lowe) Fraser-Jenk., D. borreri (Newman) Newman ex Oberh. \& Tavel, D. cambrensis (Fraser-Jenk.) Beitel \& W. R. Buck, D. pseudodisjuncta (Tavel ex Fraser-Jenk.) FraserJenk., D. schorapanesis Askerov, D. pontica (Fraser-Jenk.) Fraser-Jenk. i D. lacunosa S. Jess., Zenner, Ch. Stark \& Bujnoch (Fraser-Jenkins 2007; Jessen i in. 2011; Askerov $\mathrm{i}$ in. 2015; Asgarov i in. 2016; AsKerov \& AKCAY 2016). Na obszarze Polski dotychczas stwierdzono występowanie $D$. affinis, $D$. borreri, $D$. cambrensis i $D$. pseudodisjuncta (WozIWoda 2006a, b, c, 2007, 2010; SZCZEŚSIAK i in. 2009; PodSIEDLIK 2009, 2010; WilCZEK \& ZARZYCKI 2013; TLAŁKA 2015; ZARZYCKI i in. 2015; VADADZE i in. 2016). W ostatnim czasie opisano nowe dla nauki taksony związane z tą grupą: $D$. affinis subsp. cluthensis A. R. Church czy D. ×complexa Fraser-Jenk. nothosubsp. transsilvanica Tlałka, S. Jess., A. Rostański \& Rojek (Church i in. 2019; TlaŁkA 2019).

W obrębie gatunku Dryopteris cambrensis wyróżniane są cztery podgatunki: D. cambrensis subsp. cambrensis, D. cambrensis subsp. distans (Viv.) Fraser-Jenk., D. cambrensis subsp. insubrica (Oberh. \& Tavel ex Fraser-Jenk.) Fraser-Jenk. i D. cambrensis subsp. pseudocomplexa Fraser-Jenk. Podgatunki różnią się występowaniem lub brakiem wyraźnych ząbków na szczycie odcinków drugiego rzędu liści oraz kolorem łusek ogonków liściowych. Natomiast wspólną cechą podgatunków D. cambrensis są u-kształtne odcinki drugiego rzędu i duże kupki zarodni.

Dryopteris cambrensis obejmuje swym zasięgiem Europę północną, zachodnią, środkową i południową, od Norwegii po Portugalię i Bułgarię oraz Azję Zachodnią (Turcja) (Fraser-Jenkins 2007; TrEWrEn i in. 2014). W Europie D. cambrensis należy do grupy taksonów najmniejszej uwagi - LC (GARCÍA CRIDO i in. 2017). 